\title{
DISTRIBUTION AND BODY SIZE DIVERSITY OF EMBERIZINE SPARROWS IN Grand Teton National Park
}

\author{
MARTIN L. CODY $\downarrow$ DEPARTMENT OF ECOLOGY AND EVOLUTIONARY BIOLOGY \\ UNIVERSITY OF CALIFORNIA — LOS ANGELES
}

\section{$\checkmark \quad$ INTRODUCTION}

Over the last decade or so, we have monitored breeding bird densities over the entire range of habitats within GTNP, from grasslands and sagebrush to scrub, woodland, and forest. Many field workers, including park scientists, have contributed to the monitoring efforts. In all, there are 30 established monitoring sites, and each has been visited on average in two out of three years since 1995. Some sites, however, have been censused yearly, and on some of these the census record extends back for several decades. The monitoring work provides a rather complete assessment of the park's breeding bird communities, i.e. species over habitats among years, and to date some 160 species have been recorded in the monitoring effort, all but a handful of which are breeding birds. This report addresses specifically one prominent group of breeding birds, the emberizine sparrows and buntings.

\section{The Emberizine Data}

To date, 16 species of emberizines have been recorded at our monitoring sites. Three of these species are marginal contributors to the GTNP avifauna, and will not be considered further here: Spotted Towhee (Pipilo maculatus) occurred only in one site, Site 26/Upper Granite Canyon Spruce-fir, and in just $1 / 5$ census years; Lark Bunting (Calamospiza melanocorys) was recorded in only two sites, once each in two different years at Site 4/JLJ Grass-sage and Site7/2OL Meadow; Lark Sparrow (Chondestes grammacus) also was a singlesite and single year recording, in Site $7 / 2 \mathrm{OL}$ Meadow. Note that, while these less common species have low incidence within monitoring sites, we have encountered them more widely within the park. Of the remaining 13 species, listed in Table 1, some are widely distributed and some are more narrowly confined to specific habitat types. As a further constraint, several sites are not included here because they are undergoing successional changes in the vegetation, and thus the contingent of breeding emberizines is expected to (and does) change over time. Excluded from the site rankings are the sagebrush burn Site 5B, the Taggart Lake lodgepole burn Site 20, and the willows outgroup Site 10S (in Rocky Mountain National Park) where there has been a considerable degree of willows dieback. Also excluded from this summary are the high elevation monitoring sites in subalpine fir and alpine tundra, waterfowl counts on ponds, and the aerial-feeding swallows (Sites 27-30). However, a second willows outgroup site, Site $10 \mathrm{~N}$ in Glacier National Park, is included for its contributions to the overall patterns.

The emberizine species are listed in the leftmost column of Table 1; their body masses (in $\mathrm{g}$ ), appropriate to the subspecies in GTNP, are listed in the adjacent column. The monitoring sites represented by the columns in Table 1 are ranked from those of the lowest vegetation height and mean breeding densities of the various bird species at the 


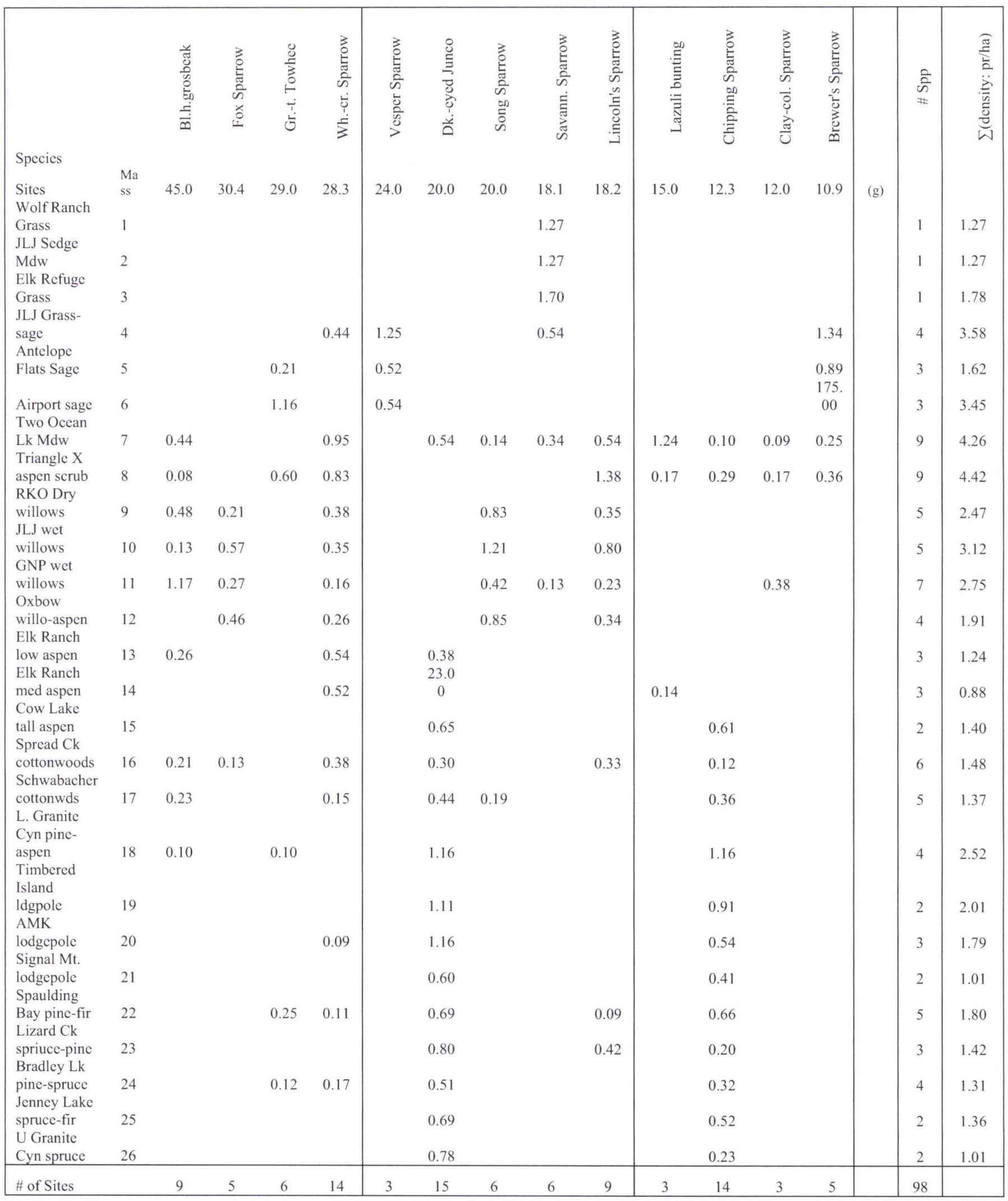

Table 1. Species identities, body masses, and distribution over GTNP monitoring sites of 13 commoner species of emberizine sparrows and buntings. 
sites, in units of $\mathrm{pr} / \mathrm{ha}$, averaged over all census years. Some of the listed species make only marginal contributions to the breeding birds of certain sites; if a species has averaged $<0.09 \mathrm{pr} / \mathrm{ha}$ at a given site over the census period, that record is removed from the data set presented here (Table 1). Row and column summaries are provided along the margins of this table: sites per species, species per site, and overall densities per species and site.

\section{Body Size and Habitat Segregation amongst the Emberizines}

The body masses of the 13 species of emberizines vary by nearly five-fold and the species segregate into four reasonably discrete body size categories. There is a single very large species (Black-headed Grosbeak Pheuticus ludovicianus, at $45 \mathrm{~g}$, denoted here by size "X"), and three large species (Fox Sparrow Passerella iliaca, Green-tailed Towhee Pipilo chlorura, White-crowned Sparrow Zonotrichia leucophrys) between 28.3 and $30.4 \mathrm{~g}-$ size "L"). The largest size class, in terms of the number of occupant species, is that of the five medium-sized species ("M"); all are between 18.2 and $20 \mathrm{~g}$ except Vesper Sparrow (Pooecetes grammineus) which at $24 \mathrm{~g}$ is somewhat larger than the other class members. Finally, four small species ("S" -three Spizella sparrows and the Lazuli Bunting Passerina amoena) round out the list, spanning the range $10.9 \mathrm{~g}$ to $15 \mathrm{~g}$. Note that, within a size group, the emberizines are broadly segregated over habitat, such that the group as a whole spans a broader range of vegetations types than does any one member species within it. This implies that species of similar sizes coexist within sites less frequently than do species of dissimilar sizes; similarly sized species tend to segregate over habitats.

In order to investigate in a more systematic fashion the tendency of emberizines of similar size to breed in different sites, and concomitantly that of dissimilarly sized species to co-occur in the same sites, a probability analysis is conducted in Table 2 , and summarized in Table 3. The upper part of Table 2 is a condensed version of Table 1, where the number of species in the four different size classes is shown over census sites left to right across the habitat gradient. Note that sites at the grassland end of the gradient support a single species (Savannah Sparrow Passerculus sandwichenis), after which the number of coexisting species build rapidly to as many as nine in the sites (Site \#s 7,8) of forb/grassland with low, open scrub, and thereafter mostly varies between 2-5 species through the woodland and forested sites.
The number of representative species in each of the four size groups is given to the left in the lower portion of Table 2. Note that, as there is no significant tendency to size groups to differ in the extent to which they are represented over monitoring sites, these species numbers may be used as predictors for a null model of sparrow community composition by body size. We can ask questions such as: given a three species (3SPP) community, what are the probabilities that one, two or three body sizes are represented in it? The lower part of the table itemizes the various body size combinations for community sizes of one to five species (1SP-5SPP), and gives the probabilities of deriving each of the as a random sample of the available species. All onespecies (1SP) sites have the medium-sized Savannah Sparrow (Table 2, lower section, left hand columns). Moving right in the table, the next columns investigate two-species (2SPP) sites. Two species pulled at random from the suite of candidates may be any one of the 9 size combinations ("Combo") listed, from SS (two small species) to LX (one large and one extra large species). Each size combination has the probability of occurrence, by chance, listed in the adjacent column (headed "Pr"). All five observations of 2SPP sites are of species from different size groups (all are "SM" communities). Moving right to the next columns, 3SPP sites are simulated by selecting triplets of species with the foregoing probabilities. There are 16 possible combinations (listed from SSS to LLX), each with their associated probabilities of occurrence, and these probabilities again can be associated with different size diversities, from one to three sizes represented. In fact, four of six observations of 3SPP sites all three size groups are represented.

Two additional sets of columns, further right in the lower part of Table 2, assess the probabilities of various body size mixes in 4SPP and 5SPP sites respectively. There are 22 possible combinations in 4SPP quartets, and 28 in 5SPP quintets (listed from SSSSM to MLLLX); in the latter case, there are 1349 ways of generating the different combinations, and these combine to yield the probabilities listed. In fact, three of the four 4SPP sites in the data set support species combinations with three or four body sizes, and in the four observations of 5SPP species sets, all have the characteristics of the $\geq 3$ sizes, with $\leq 2$ representatives per size category. These figures might happen by chance, and to examine this possibility we move to Table 3 in which the data are summarized. Here the expected and observed numbers of sites with different numbers of species, and with various ranges in body size representation, are compared. Included here also is the single 6SPP 


\begin{tabular}{|c|c|c|c|c|c|c|}
\hline & $\stackrel{i}{\sim}$ & - & - & & & $\sim$ \\
\hline & $\approx$ & - & - & & & $\sim$ \\
\hline & $\stackrel{\sim}{\sim}$ & - & - & $N$ & & + \\
\hline & $\ddot{\vec{\lambda}}$ & - & $N$ & & & $m$ \\
\hline & तี & - & $N$ & $N$ & & $\ln$ \\
\hline & $\bar{\sim}$ & - & - & & & $N$ \\
\hline & 2 & - & - & - & & $m$ \\
\hline & $\propto$ & - & - & & & $\sim$ \\
\hline & $=$ & - & - & - & - & t \\
\hline & $\stackrel{\circ}{\circ}$ & - & $N$ & - & - & in \\
\hline & $\cong$ & - & $N$ & $N$ & - & 6 \\
\hline & \pm & - & - & & & $N$ \\
\hline & $\cong$ & - & - & - & & $m$ \\
\hline & $\simeq$ & & - & - & - & $\mathrm{m}$ \\
\hline & $=$ & & $N$ & $N$ & & $\nabla$ \\
\hline & 으 & - & $m$ & $N$ & - & In \\
\hline & 은 & & $N$ & $N$ & - & in \\
\hline & $a$ & & $N$ & $N$ & - & in \\
\hline & $\infty$ & $\nabla$ & N & $\sim$ & - & a \\
\hline & $r$ & $\nabla$ & $m$ & - & - & a \\
\hline & 6 & - & - & - & & $m$ \\
\hline & in & - & - & - & & $m$ \\
\hline & $\nabla$ & - & $N$ & - & & $\nabla$ \\
\hline & $m$ & & - & & & - \\
\hline & $\sim$ & & - & & & - \\
\hline$\underline{\underline{n}}$ & - & & - & & & - \\
\hline & $\frac{\frac{1}{N}}{\omega}$ & $\sum_{\infty}$ & $\stackrel{\rho}{\underline{\mid}}$ & 0 & $\frac{1}{x}$ & $\omega$ \\
\hline
\end{tabular}

ڤn

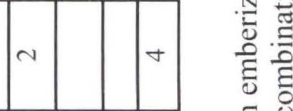

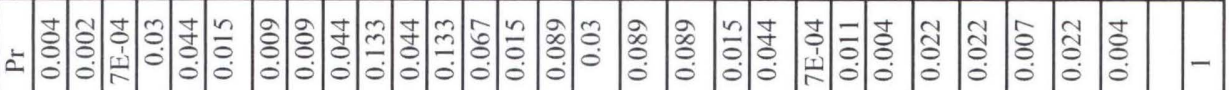

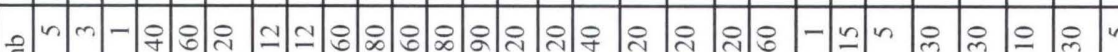
(2)

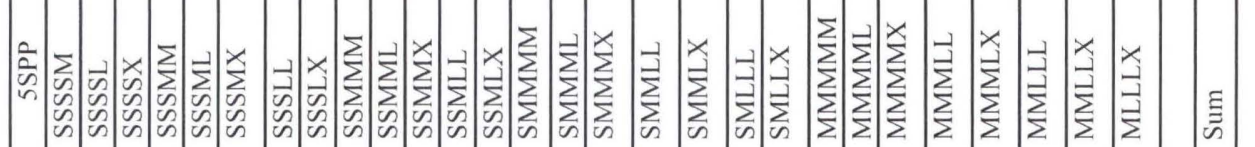
ڤิ

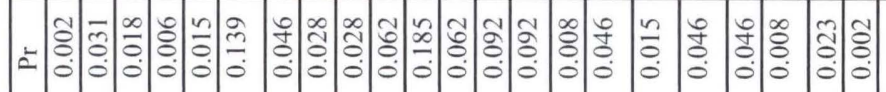

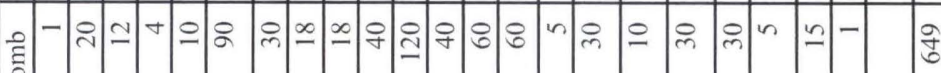

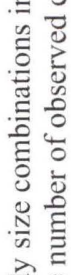

突

苛 :

$\stackrel{0}{0}$

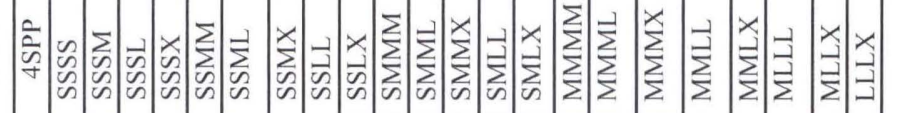

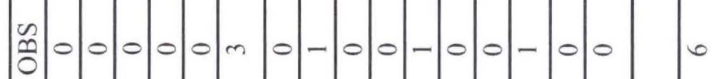

$=$ =

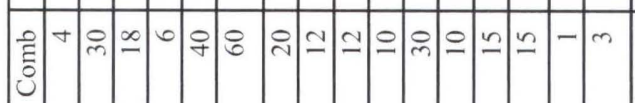

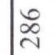

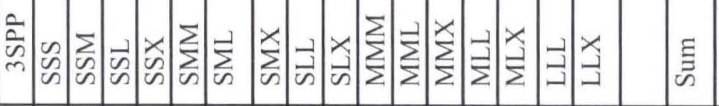

竞

严

马 $\stackrel{g}{\Xi}$

冚

g.

z

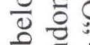

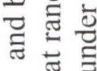

$\dot{x} \cong \overline{0}$

․ㅡㄹ

i

if 0

츠 क क

듭 겅

○.

$\overline{\text { 死 }}$

है

की

के

ñ 000000

40

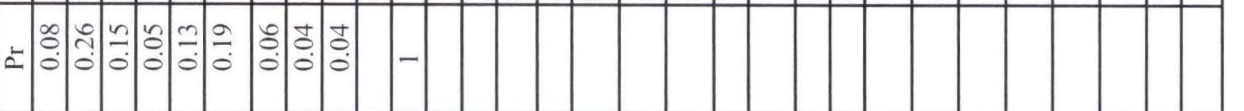

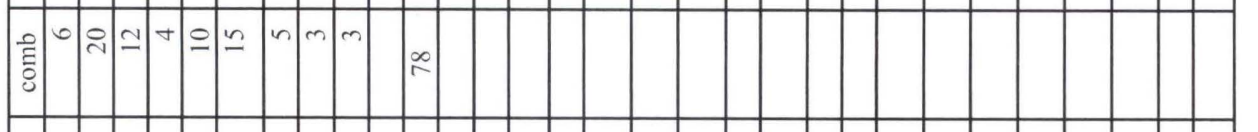

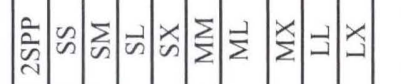

$\approx 0.000 \mathrm{~m}$

$\frac{2}{\frac{2}{2}}+\infty m-$

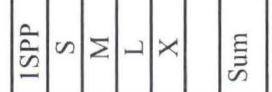

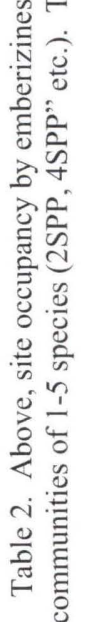


community, which has species representative of all four size classes. Note that the three sites with $>6$ emberizines (Site 7: Two Ocean Lake Meadow, 9SPP; Site 8: Triangle X aspen scrub, 9SPP; and Site 10N: Coonsa Ck Willows, GNP, 7SPP) have species representative of all four body size classes. The simplest test (to which we are limited by dint of low sample sizes) is to ask to what extent to communities of different species numbers support the maximum body size range possible? That is, to what degree do 2SPP communities contain two different body sizes, 3SPP communities three body sizes, and so on up to four body sizes (the maximum range). A simple Chisquared test is included at the bottom of the table, and this shows that there is a statistically significant tendency for the different sparrow communities, with different species composition and different species numbers, to cover the widest possible range of body sizes.

\section{Emerizines in a Seasonal Context}

Virtually all of the breeding emberizines of GTNP leave the park for the winter, and many winter thousands of kilometers to the south. In fact, rather more research has been conducted on the wintering ecology of emberizines than on there breeding ecology, especially in a community context. Fretwell (1972) initially suggested that populations in many sparrow species might be limited by winter resources rather than by those at the breeding site, and he supported his contention with data on Field Sparrows (Spizella pusilla) and a broad review. Pulliam (1975, 1983) and his associates (Pulliam \& Brand 1975, Pulliam \& Mills 1977) conducted intensive research on wintering emberizines 30 years ago, much of it based in the arid desert grasslands of the southwest USA where it is likely that at least some of the GTNP breeding species spend the winter. Notably, the Spizella species, Savannah Sparrow, Vesper Sparrow, Lark Sparrow and other GTNP breeding emberizines were found at his Research Ranch study site in southeastern Arizona. Pulliam's research associated body size with culmen size, and in turn culmen size with the ability to harvest and ingest seeds of different sizes. There were also correlations of body size with the use of space, distribution over vegetation types, and the extent of co-occurrence of different and differently-sized wintering species. It appears that, even though there is support for the argument that emberizine populations are sometimes, perhaps often, limited by winter site resources, there is also substantial evidence that emberizines segregate in the breeding season by habitat and feeding ecology, and by phenotypic characters associated with body size that affect foraging ecology and predator avoidance (e.g. Cody 1968). Thus the size patterns described here are interesting but not unexpected.

\begin{tabular}{|l|l|l|l|l|l|l|l|l|l|l|}
\hline \multicolumn{10}{|c|}{ BODY SIZE RANGE } \\
\hline COMM & & 1 SIZE & \multicolumn{2}{l|}{ S SIZE } & \multicolumn{2}{l|}{ 3SIZE } & \multicolumn{2}{l|}{ 4SIZE } \\
\hline SIZE & $\mathrm{n}$ & $\mathrm{E}$ & $\mathrm{O}$ & $\mathrm{E}$ & $\mathrm{O}$ & $\mathrm{E}$ & $\mathrm{O}$ & $\mathrm{E}$ & $\mathrm{O}$ \\
\hline 1 SPP & 3 & 3 & 3 & - & - & - & - & - & - \\
\hline $2 \mathrm{SPP}$ & 5 & 1.22 & 0 & 3.78 & 5 & - & - & - & - \\
\hline $3 \mathrm{SPP}$ & 6 & 0.31 & 0 & 3.44 & 2 & 2.24 & 4 & - & - \\
\hline $4 \mathrm{SPP}$ & 4 & 0.04 & 0 & 1.11 & 1 & 2.48 & 2 & 0.37 & 1 \\
& & & & & & & & & - \\
\hline $5 \mathrm{SPP}$ & 4 & 0 & 0 & 0.58 & 0 & 2.61 & 3 & 0.80 & 1 \\
\hline $6 \mathrm{SPP}$ & 1 & - & - & 0.05 & 0 & 0.71 & 0 & 0.24 & 1 \\
\hline
\end{tabular}

Maximum size diversity in 2SPP-6SPP communities (Boxed is found in 12/20 cases (expected number $=7.43$ ). Chi-square with $1 \mathrm{df}+4.47 ; \mathrm{p}<0.05$ that this occurs by chance

Table 3. Sparrow community sizes (left-hand column) may support a range of different body sized (see column heads across the table). The second column gives the number of examples of the different community sizes in the GTNP monitoring data. Entries in the table are the expected (E) and observed $(\mathrm{O})$ numbers of the different body size ranges. There is a statistically significant tendency for the communities to support the maximum size range (e.g. 3 sizes in a 3 SPP community).

\section{$\downarrow$ Literature Cited}

Cody, M.L. 1968. On the methods of resource division in grassland bird communities. Amer. Natur. 102: 107-147.

Fretwell, S. 1972. Populations in Seasonal Environments. Monogr. Pop. Biol. \#5, Princeton Univ. Press, NJ.

Pulliam, H.R. 1975. Coexistence of sparrows: a test of community theory. Science 184: 474476.

Pulliam, H.R. 1983. Ecology community theory and the coexistence of sparrows. Ecology 64: $45-52$.

Pulliam, H.R. and M.R. Brand. 1975. The production and utilization of seeds in plains grasslands of southeastern Arizona. Ecology 56: 1158-1166.

Pulliam, H.R. and G.S. Mills. 1977. The use of space by sparrows. Ecology 58: 13931399. 